Final version in Jennifer Lackey, ed., Essays in Collective Epistemology, Oxford University Press (2014). Please feel free to email me for a pdf of the published version: david.christensenebrown.edu

\title{
Disagreement and Public Controversy ${ }^{1}$
}

Unfortunately for the good sense of mankind, the fact of their fallibility is far from carrying the weight in their practical judgment which is always allowed to it in theory; for while everyone well knows himself to be fallible, few think it necessary to take any precautions against their own fallibility, or admit the supposition that any opinion of which they feel very certain may be one of the examples of the error to which they acknowledge themselves to be liable.

— J.S. Mill, On Liberty

J.S Mill's famous defense of free speech makes several arguments, but one of the most interesting springs from his appreciation of human fallibility. This strand of argument is straightforwardly epistemic: Mill would have us treat the opinions and arguments of those who disagree with us as an epistemic resource, which furnishes us with a means for taking precautions against our own fallibility.

More recent discussion of disagreement in mainstream epistemology has not been aimed at drawing conclusions in political philosophy, but at better understanding what sort of purely epistemic role disagreement should play. Most of the debate has revolved around the question of what, if any, effect the disagreement of others should have on the confidence with which one holds one's own beliefs. (Answers to this question may be called "Conciliatory" to the extent that they hold that disagreement often requires us to be less confident in our beliefs than we

\footnotetext{
${ }^{1}$ For helpful discussion or comments on drafts, I'd like to thank Nathan Ballantyne, Jennifer Lackey, Andrew Rotondo, Maja Spener, Henry Swift, an anonymous referee for Oxford University Press, and audiences at the Second Copenhagen Conference in Epistemology, the Brandeis Graduate Student Brown Bag series, and the Conference on Epistemology of Groups at Northwestern University.
} 
would be absent the disagreement. They may be called "Steadfast" to the extent that they deny this.) But in this literature, as in Mill, the epistemic significance of disagreement is often tied to considerations of our epistemic fallibility.

Many recent papers on disagreement open by mentioning issues about which there is considerable public controversy; examples from philosophy, morality, politics and history are commonly cited. But while disagreement's epistemic implications for issues of public controversy is part of what gives the issue its interest, many papers quickly move on to focus on very simple, artificial cases involving just two people. It's not that participants in the debate are mainly interested in these examples: in fact, people on opposite sides often agree about whether, in a given example, conciliation is called for. What they're interested in, and what they disagree about, is what sort of reasons for changing belief might be provided by the disagreement of others in simple cases. The hope is that by understanding the rational response to disagreement in the simple cases, we'll get some insight into what the rational response is in the more complex ones involving the public controversies among groups that give the issue much of its urgency.

In this paper, I'd like to focus on a particular theoretical approach to disagreement: a kind of conciliatory approach that sees disagreement as often having important implications for rational belief. And I'd like to look at how this view might apply to public group controversies in philosophy and in politics. It turns out that though this approach springs from the same motivations as Mill's approach to free speech, it yields results in many cases that are opposite to those Mill emphasized. I'll also argue that the appeal of conciliating epistemically will often be stronger for group disagreements than for artificial two-person cases. Finally, I'll look at some ways in which reacting rationally to disagreements of the sort often found in politics can be a particularly difficult and nuanced matter. 


\section{Independence-Based Conciliationism}

Having said all that, let me set up the position I want to discuss by reference to a pair of particularly simple artificial examples.

Music Contest: I'm attending a contest for high-school musicians. After hearing all the performers, and becoming quite convinced that Kirsten's performance was significantly better than Aksel's, I hear the man next to me express just the opposite opinion. But then I find out that he is Aksel's father.

Here, it seems that I need not revise my belief much at all.

Mental Math: I've been regularly going to dinner with my friend for many years; we always divide the bill evenly, tip 20\%, and figure our shares in our heads. We almost always agree, but when we've differed, we've checked with a calculator, and have been right equally often. Tonight seems typical: neither of us seems especially tired or alert; neither has had more than the usual wine or coffee. I divide the bill and become confident that our shares are $\$ 43$. But my friend announces that she got $\$ 45$.

Here, it seems that I should become much less confident of my belief about my share of the bill. And I think this is true even if, this time, I'm the one who happens to be correct.

In the first case, it seems that the reason I need not worry about the other person's disagreement is that I have good reasons for thinking him less likely than I am to have reached the correct opinion on the disputed matter: I know that parents are disposed to overrate the achievements of their children. But, one might ask, don't I also have reason in the Mental Math case to think my friend less likely than I to have come up with the right answer? Why can't I say, "Well, despite our equally good track records, I have reason to think that, on this particular 
occasion, she's the one who made the mistake. After all, as the evidence shows, my share of the bill is $\$ 43$, and she believes otherwise!’?

It seems clear that this last sort of response to disagreement is illegitimate. To invoke it would intuitively amount to begging the question-which is raised by my friend's disagreement - of who made the mistake.

But if I cannot downgrade my friend's opinion in the restaurant by relying on my belief about my share of the bill, how could it be reasonable to rely on my (also fallible) belief about parental bias patterns in downgrading the other man's opinion in the Music Contest case? I may, after all, be even more fallible in my opinions on parenting psychology than I am in my opinions on restaurant check division. The answer, it seems to me, depends on the focus of the potential doubt about my reasoning prompted by disagreement. In relying on my belief about my share of the bill to dismiss disagreement in the Mental Math case, I rely on the very bit of reasoning-my calculation of my share from the total amount of the check - which the disagreement threatens to cast doubt on. But in relying on my general psychological beliefs to dismiss disagreement in the Music Contest example, I do not rely on my particular assessments of Kirsten's and Aksel's performances.

This suggests that in trying to give a general theoretical account of the rational response to disagreement, we'll need to take into account the extent to which our assessment of the epistemic significance of another's disagreement is independent of the reasoning which that disagreement may call into question. The following (admittedly vague) account captures the basic idea. Because I think it has Conciliationist consequences, I'll call it Independence-Based Conciliationism (IBC): 
(IBC): In responding to disagreement, one should assess the epistemic credentials of the parties involved in a way that's independent of one's own initial reasoning about the matter in question. One should moderate one's (pre-disagreement) belief to the extent that one has epistemically strong, dispute-independent reason to think that those who disagree are well-informed and likely to have reasoned correctly from their evidence, as compared with those who agree.

This formulation is vague and highly simplified, to avoid delving into various complications I wish to avoid here. ${ }^{2}$ But to fix ideas, let us interpret it so that in disagreements between equally-confident disputants, when I have very strong dispute-independent reason to think that those who disagree with me are equally well-informed and equally likely to have reasoned correctly as those who agree with me, then I should be much less confident in the disputed proposition than I'd otherwise be, perhaps withholding belief. Note that the view requires conciliation when I have strong positive, dispute-independent reasons for granting epistemic respect to those with whom I disagree, not whenever I lack dispute-independent reasons for thinking less well of them (the importance of this will emerge below).

IBC helps explain why we can dismiss disagreement in the Music Contest case, but not in Mental Math. In prohibiting one from brushing off disagreement by using the very reasoning that's potentially put into question by the others' dissent, IBC seems to capture our sense that in responding to disagreement, we must avoid begging the question of whether we've made a mistake. Obeying IBC thus essentially gives us a way—to use Mill's terms—of taking precautions against our own fallibility.

\footnotetext{
${ }^{2}$ I've tried to do a little better in (Christensen 2010). Some other papers explicitly supporting independence-based responses to disagreement include Christensen (2007), Elga (2007), and Kornblith (2010).
} 


\section{IBC and Group Disagreements: Controversies in Philosophy}

Naturally enough, many philosophers writing on disagreement are interested in whether the rampant disagreement we seem to see in most areas of philosophy should occasion widespread retreat from confident belief. The "seem" here is to acknowledge that some apparent disagreement in philosophy may be only apparent, the result of people talking past one another (see Sosa (2010), Chalmers (2011). It seems reasonable to assume, however, that there is enough genuine disagreement in philosophy to make the question of how to respond to real disagreements an important one, even if it will sometimes not be obvious whether a given disagreement is substantive or verbal. ${ }^{3}$

In some ways, the case for conciliation in philosophy seems weaker than the case of conciliation in the Mental Math case. The latter case features exact parity of informedness: we can both see the total bill perfectly clearly. And it features incredibly strong evidence of equal reliability, in the exact type of reasoning involved in the disputed issue: we have settled a long series of past check-dividing disagreements with a calculator, and we're equally prone to error in scenarios extremely similar to the current one. In typical philosophy cases, by contrast, wellinformedness is somewhat amorphous: it typically depends on familiarity with, and understanding of, substantial chunks of the relevant literature, but exactly what literature is relevant is somewhat vague, as are degrees of familiarity and understanding. And of course the group nature of the controversy means, among other things, that I'm unlikely to know all that much about all of the people who disagree with me (or, for that matter, the ones who agree with me). Finally, and perhaps most important, there's nothing remotely like a clear track-record of

\footnotetext{
${ }^{3}$ Thanks to an anonymous reader for pointing out the need for making this point.
} 
accuracy for any of us, since there's no philosophical analogue of a calculator to tell us who's been right and who's been wrong in previous judgments. So we lack a clear objective way of measuring an agent's likelihood of reasoning correctly about philosophical matters.

Nevertheless, it seems to me that a strong case can be made, given IBC, that many of us should be much less confident in our philosophical beliefs than we often seem to be. To see why, let us consider a particular example: the status of Multi-Premise Closure (hereafter "Closure") principles for rational categorical belief. When I consider the arguments for and against, it seems to me pretty clear that Closure is false. But many other epistemologists think otherwise. How should I react to these facts? I think three points are worth emphasizing here:

(a) The first point is that I do have good reason to have as much epistemic respect for my philosophical opponents as I have for my philosophical allies and for myself. Obviously, there's no scorecard I can use to rate the reliability of different epistemologists. But this doesn't mean I have no way (independent of the Closure dispute) of assessing the epistemic credentials of epistemologists.

In some cases, I have specific information about particular people, either on the basis of general knowledge or from reading or talking to the epistemologists in question. This includes information about education; about command of the literature; and about skill in argument and analysis. In some cases, I may even have information about the person's intellectual character (open-mindedness, fairness, intellectual honesty, and so on). These are the sorts of factors that I take to be responsible for a person's ability to reach accurate beliefs about philosophical issues.

Moreover, even where I lack this sort of individualized information about some of the other philosophers in the dispute, it seems that I have strong reason to doubt that, in general, the more honest, or more diligent, or better-read philosophers are the ones who agree with me about 
Closure. One reason is simply that the individuals I do have information about certainly don't fit any such pattern. But another reason derives from the group nature of philosophical controversy. It seems clear that the groups of people who disagree with me on various philosophical issues are quite differently composed. Many who are on my side of one issue will be on the other side of different issues. With this structural feature of group disagreement in philosophy in mind, it seems clear that it could hardly be rational for me to think that I'm part of some special subgroup of unusually smart, diligent, or honest members of the profession.

When I think in this way about the people who disagree with me about Closure, I believe that I do get strong, dispute-independent reason to think that those who disagree with me are as well-informed, and as likely to have reasoned correctly from their evidence, as those who agree with me. If that's right, then it would seem that IBC implies that I should not have much confidence at all in the falsity of Closure. Indeed, it would seem that I should probably have few, if any, confident beliefs at all about philosophically controversial matters!

(b) The second point involves a different way in which persistent patterns of disagreement within a group of investigators can pose an epistemic problem. This sort of case for drastically reducing my confidence in controversial philosophical theses has been made by several writers; the version I'll sketch here is perhaps closest to the one developed by Hilary Kornblith $(2010)^{4}$. When we look at professional philosophy, its failure to reach consensus on important issues is striking. As Kornblith points out, this lack of consensus indicates that whatever methodology philosophers use is not a reliable way of reaching philosophical truth.

\footnotetext{
${ }^{4}$ See also Goldberg (2009, 2013), Christensen (2007), Fumerton (2010) and Brennan (2010) (though Brennan focuses more on whether someone new to philosophy would be justified in studying the arguments and coming to hold philosophical opinions).
} 
And recognition of this, it seems, should make us skeptical of our own applications of that methodology to arrive at confident philosophical conclusions.

The power of this argument also ultimately depends, I think, on an independence principle - on assuming that our evaluation of the epistemic credentials of others, for the purpose of deciding whether to modify our beliefs in response to their disagreement, must be independent of our own reasoning on the disputed matters. ${ }^{5}$ After all, I wouldn't have to worry about wide dissensus in philosophy if I could rationally take myself to be special. The independence requirement prevents me from reasoning as follows, even in cases where my original reasoning on the disputed topic happens to be correct: "Well, as the arguments show, Multi-Premise Closure principles are false. And I have come to the conclusion that they're false. So, whatever general problems there are with philosophical methodology, they apparently haven't led me astray in this case!"

Disallowing this sort of response makes sense precisely because it would beg the question to answer doubts about the cogency of a certain bit of reasoning I did by relying on that very bit of reasoning. I would not really be taking seriously the possibility that my reasoning, rather than that of the other philosophers, was faulty. Thus it seems that taking ourselves to be fallible in the same way we see others as fallible is all we need to argue for severe limitations on the rational confidence we can have in controversial theses in philosophy. ${ }^{6}$

\footnotetext{
${ }^{5}$ Kornblith (2010) does endorse an independence requirement.

${ }^{6}$ This is not to deny that in philosophy, it may be good to take positions, defend them as if I believe them. If there's some hope of making progress in philosophy, it's not implausible that we need people vigorously defending positions in a way that people wouldn't if they didn't have more confidence in their positions than is rationally warranted. There may be some good - even epistemic good - in our epistemic hubris. It also may be argued that the sort of assertion typically involved in philosophical debate need not be based in justified belief to be legitimate; see Frances (2010), Goldberg (2013).
} 
c) The third reason that conciliatory pressure may be greater in group disagreements concerns the unavailability, in group contexts, of a particularly nice way of rationally dismissing disagreement in certain two-person cases.

Some critics of IBC have argued that it gives the wrong results in cases where one starts off with extremely high rational confidence. Jennifer Lackey (2010) gives examples of beliefs about elementary math and about the location of a favorite restaurant. Suppose I've been frequenting My Thai for many years, and I am extremely confident that it's on Michigan Avenue. One day my friend, who's just as familiar with the city, and also a frequent My Thai patron, tells me he's extremely confident it's on State Street instead. Lackey argues that in this sort of disagreement, there's an asymmetry that makes it rational for me to conclude that it's my friend who's wrong in this case. In situations of this sort, it seems likely that one of us is badly malfunctioning. She points out that I may know full well that I'm not drastically sleep-deprived, that I don't remember taking drugs or drinking a lot recently, or having psychotic hallucinations. I would add to Lackey's list that I also know I'm sincere: I'm not lying or joking about what my belief is about My Thai's location. But I have much less firm reason to believe these things about my friend. So insofar as I have very good justification for my initial belief, the right thing to conclude in such a case is that it's highly likely that my friend is badly malfunctioning (or insincere). The same response can be made, even more persuasively, for cases like $2+2=4$, where one starts out with even greater rational confidence in one's opinion. Lackey calls the considerations I use here to break the symmetry and resist the undermining power of disagreement "personal information". 
Lackey and I disagree about whether this invocation of personal information is consistent with IBC. ${ }^{7}$ But I won't pursue that question here. Instead, I want to note that this sort of response, which ameliorates the corrosive power of disagreement so nicely in certain two-person cases involving extremely high rational credence, seems to be much less applicable in the context of disagreements among groups.

Now even before considering features characteristic of group disagreement, I should note that one might reasonably hold that personal-information-based dismissal will rarely be appropriate in philosophical disagreements anyway. After all, the personal-information-based argument for steadfastness in the elementary math case depends crucially on the subject's initial extremely high level of rational confidence in her belief - this is required to support the claim that the disagreement is likely due to severe malfunction or insincerity. But group disagreements in philosophy tend not to revolve around issues as obvious as the sum of two and two, so it's not clear that the personal-information-based argument will often get off the ground. I think this point is basically right. But I suspect that we've all had conversations with colleagues who seem to regard their own takes on some issue as being about as obvious as two plus two—or at least as if their takes should be that obvious to anyone who bothered to think the issue through. And many philosophers seems as confident in their philosophical views as they are about the location of their favorite restaurants. So I want to put this point aside. It seems to me that even if one does take one's initial view on, say, free will to be overwhelmingly obvious, one cannot use this high level of initial confidence, in combination with personal information, to resist the undermining power of disagreement among large groups of philosophers.

\footnotetext{
${ }^{7}$ See Christensen (2010) for an argument that this sort of resistance to conciliating is consistent with evaluating my friend's epistemic credentials in a way that's independent of our dispute.
} 
The reason for this is explained nicely by Maja Spener (2011), in discussing uses of controversial introspective reports in the philosophy of perception. As Spener argues, even if it makes sense to use asymmetry of personal information to conclude that one's friend is malfunctioning in cases like Lackey's, the asymmetry diminishes drastically in the group context. Clearly, one lacks personal information about all the other people on one's own side of the dispute, as well as about all the people on the other side. Moreover, in order to explain the disagreement by reference to the sort of insincerity or malfunction that can be eliminated by personal information in one's own case, one would have to suppose that it affected all of one's opponents, and not one's allies. As Spener puts it, "[i]t would be ridiculous to claim that all the disagreeing partners happened to be intoxicated, cognitively malfunctioning, joking or inattentive at crucial junctures" $(2011,278)$. So it seems that in the group context, the power of personal information to defuse disagreement is diluted to the point of washing out.

Now it should be made clear that the point here is not that severe malfunction or insincerity cannot occur at the group level, or that there's no asymmetry at all in the group situation. It's that in the vast majority of such cases, one's own personal information will not be of significant use in selectively attributing malfunction or insincerity to one's opponents. Consider a disagreement in a field with 10 professors at various institutions claiming that $\mathrm{P}$, and 10 others claiming that $\sim \mathrm{P}$, and suppose I'm in the former bunch. I can, of course, rule out insincerity and particular sorts of severe malfunction for myself, and not for any of the others. So there is at least a bit of asymmetry. But can I credibly explain the group disagreement by reference to the sort of insincerity or malfunction that I can rule out in my own case? This would involve (1) believing the 10 philosophers on the other side were insincere or malfunctioning in some way such that if I were malfunctioning in that way, I'd be able to detect it; and (2) not 
believing this about the 9 other philosophers on my side of the dispute. This is not impossible, but it strikes me as highly implausible — much more implausible than selectively believing that my single friend is insincere or malfunctioning in one of those ways in a two-person disagreement. It's worth noting that there are many other explanations for the group disagreement, including our general unreliability on the issue in question, biases, influences from our education, and more severe malfunctions that don't reveal themselves to their victims in any way. But those are factors I can't eliminate in the my own case by personal information, so they are of no use in selectively downgrading the opinions of those who disagree with me. ${ }^{8}$

One can, of course, imagine disagreements between two groups where personal information would be effective. Suppose, e.g., that one has good reason to believe that every member of one group or the other has been paid to express a certain opinion, and one also knows about oneself that one has not been paid. But such examples are contrived, and don't affect the point that the sort of disagreements we see in philosophy, or in other disagreements involving large groups, will not in general be dismissible on personal-information grounds. ${ }^{9}$

In sum: the example of philosophical disagreement provides a nice illustration of some ways in which the group nature of certain disagreements can present a stronger case for reduced

\footnotetext{
8 Thanks to Jennifer Lackey for prompting me to make this case more carefully. (Of course this should not be taken to imply that she is convinced.)

${ }^{9}$ It also should be noted that some features of philosophical disagreements which help block the personal-information-based argument for steadfastness can occur outside the group context. For example, philosophical disagreements often persist over long periods of time. If a two-person disagreement persisted over a long period of time, many of the malfunction-related explanations for the disagreement would be less plausible, so the power of personal information to support steadfastness would be reduced. (Thanks to an anonymous reader for making me see this; I should note that Spener makes a related point.) That said, it remains true that the group nature of many disagreements is by itself sufficient to preclude significant reliance on the personalinformation-based argument for steadfastness.
} 
confidence than is present in the two-person toy cases on which the literature tends to concentrate. True, in many such cases, we will lack the sort of clear track-record evidence we have in the Mental Math case. But we may yet have good reasons to believe that those who disagree with us are just as likely to get things right as are those who agree, especially when the claim that we are part of some especially reliable sub-group is implausible.

Moreover, if we set up the argument for reducing confidence as Kornblith does, it doesn't rest on commitment to any very specific identification of what makes one good at ferreting out truth in the relevant domain. And persistent disagreements among group members provide trackrecord-style reason to worry about the relevant methodology — a reason that doesn't depend on a referee scoring individual judgments right or wrong. Insofar as we take the controversial questions in a domain to have objectively right and wrong answers, persistent widespread disagreement of group members is enough to show that the methods the group employs are not generally reliable. ${ }^{10}$

Finally, insofar as one is tempted to resist conciliatory views of disagreement on the grounds that personal information can license steadfast responses to certain cases, it seems clear that one's reasons for resisting conciliation will not apply to the cases many of us cite as motivating our interest in the epistemology of disagreement: well-known disagreements about philosophy, politics, morality, history, and so on. The fact that the disagreements occur in the context of large groups makes personal information largely irrelevant. The group nature of certain sorts of disagreement thus turns out, on balance, to strengthen the case for conciliation significantly.

${ }^{10}$ Of course, this would seem to apply to the methods I'm employing here. For some discussions of the self-undermining problem for conciliatory views of disagreement, see Elga (2010), Frances (2010), Christensen (2013) and Weatherson (2013). 


\section{Fallibility and the Epistemic Value of Disagreement: Mill vs. IBC}

As noted earlier, Mill's position also stems from a concern with our epistemic fallibility. Mill points out quite convincingly that fallible thinkers are prone to rely on false beliefs, and end up suppressing true beliefs. But he argues that we should not take acknowledgment of our fallibility to paralyze us - to prevent us from taking any actions at all based on our beliefs. So then why not act on our beliefs by suppressing beliefs we take to be false? According to Mill, it is precisely by allowing one's beliefs to confront vigorous dissent that one can achieve the level of rational certainty that would justify acting on one's beliefs. So this argument for free speech rests on the epistemic benefits of confronting disagreement:

Complete liberty of contradicting and disproving our opinion is the very condition which justifies us in assuming its truth for purposes of action; and on no other terms can a being with human faculties have any rational assurance of being right. $(1859,24)$

In the case of any person whose judgment is really deserving of confidence, how has it become so? ... Because it has been his practice to listen to all that could be said against him; to profit by as much of it as was just, and expound to himself, and upon occasion to others, the fallacy of what was fallacious. ... The steady habit of correcting and completing his own opinion by collating it with those of others, so far from causing doubt and hesitation in carrying it into practice, is the only stable foundation for a just reliance on it: for, being cognizant of all that can, at least obviously, be said against him, and having taken up his position against all gainsayers - knowing that he has sought for objections and difficulties, instead of avoiding them, and has shut out no light which can be thrown upon the subject from any quarter - he has a right to think his judgment better than that of any person, or any multitude, who have not gone through a similar process. $(1859,25)$ 
Thus, for Mill, it seems that exposure to dissent is epistemically valuable because it can help us compensate for our fallibility, thus allowing us to become more rationally confident in our opinions.

This account of the epistemic importance of disagreement presents a stark contrast with the account which IBC gives in the case of public disagreements in philosophy. Consider what Mill might say about my opinion on Closure. I have read and thought more carefully about this issue than I have about most others. I've studied arguments from the literature on both sides, and talked the issue through with epistemologists of both persuasions. I've published my own antiClosure arguments. And I've read and thought carefully about responses from those who are thoroughly unconvinced by my arguments. When I consider all these arguments, as carefully and honestly as I can, it still seems to me pretty clear that Closure is false. And it seems to me that I can see the problems in others' arguments for Closure, and in their criticisms of my arguments against Closure; indeed, I have expounded the fallacies of such arguments to myself, and, upon occasion, to others. So it would seem that, on Mill's account, my encounters with articulate, well-informed and intelligent defenders of Closure have actually put me in a position to be more rationally confident of my position.

Not so, according to IBC; in fact, quite the reverse. For I do have a great deal of epistemic respect for many Closure-supporters. When I bracket their misguided views on Closure (and closely-related matters), I see many of them as my philosophical equals or betters: at least as likely as I am to succeed in getting at truths in philosophy. For reasons rehearsed in the previous section, obeying IBC would mean my reducing my confidence in the falsity of Closure way below what it would be absent the disagreement of those fellow epistemologists. Given the 
distribution of opinion on the topic among philosophers I have every reason to respect, I should probably withhold belief on the topic.

Clearly, IBC embodies a more radical way of reacting to our fallibility. In philosophy, we've all paid at least lip service to the injunction that one must read and take seriously the arguments and opinions of others, as a condition of responsible belief. We pride ourselves in this sort of open-mindedness or epistemic modesty, even as we take strong positions on controversial issues. ${ }^{11}$ But the degree of epistemic modesty supported by IBC is far less comfortable.

Yet it also bears noticing that the fundamental motivation behind IBC is not far away from Mill's. Mill's position stems from the realization that we often err by overlooking, or failing to attend carefully to, arguments opposing what we're inclined to believe. And engaging carefully and honestly with those who disagree is the natural precaution against this sort of fallibility. IBC flows from the realization that our fallibility runs a bit deeper than Mill suggests: we also often err in coming to settled, all-things-considered judgments, even after the most careful reflection and conscientious engagement with our opponents. This is obvious, when one looks at all the mutually incompatible opinions stably held by various groups in philosophy-it seems undeniable that a lot of us have failed to reach the truth on a lot of the issues we study. To my mind, the more radical-seeming consequences of IBC simply represent the natural precautions suggested by this more thoroughgoing acknowledgment of our fallibility. ${ }^{12}$

\footnotetext{
${ }^{11}$ I of course would not claim that all those who profess to take seriously the opinions of others actually do so. But I think that most philosophers at least make some steps in this direction in mostly good faith.

${ }^{12}$ As Nathan Ballantyne has pointed out to me, one might actually take Mill's position to require substantial withholding of opinion on controversial matters, in a quite different way. On many issues, I have not seriously engaged all (or even most) of the detailed arguments advanced by those holding contrary views. If serious engagement with "all that can ... be said" against my opinions were necessary for rational belief, I would fail to meet this standard pretty frequently.
} 
Fortunately, little of practical importance depends on whether one or another epistemologist arrives at the truth about Closure. Even if most of us have irrational amounts of confidence in our own pet views, this does not seem likely to do anyone serious harm. Unfortunately, analogous claims cannot be made for controversial political issues. So it is worth asking: do the sorts of considerations which argue for widespread belief-withholding about the positions debated in academic philosophy carry over to recommend a similar amount of withholding with respect to positions that are subject to political controversy?

Trying to give a blanket answer to that question at this point strikes me as unpromising, since political controversies differ from one another in ways that seem to me to have important epistemic implications. Instead, I'd like to look at some particular examples, with an eye towards identifying the sorts of factors that would help us arrive at reasonable answers in particular cases.

\section{IBC and Public Controversies in Politics 1: Evolution}

One thing that makes the Conciliationist argument so strong in philosophy is that I think of my opponents as being just as fair-minded, unbiased, honest, and well-informed as I am. Of course, there may well be arational factors influencing most philosophers' beliefs: where a given philosopher went to graduate school, which views she happened to latch onto early in her intellectual development, etc. But it does not seem that I can cite these sorts of factors selectively to downgrade my philosophical opponents; my views are equally a product of such arational factors. In a general sense, I think I have very good reason to think of my philosophical opponents as my peers with respect to aptitude, informedness, and intellectual virtue.

But the contrast remains between this reading of Mill's position and IBC. On the former, the reason I fail to meet the standard for rational belief is that I've not engaged sufficiently with those who disagree. Disagreement remains a source (albeit untapped) for increasing rational confidence, not a source of its undermining. 
It goes without saying, I suppose, that people in political controversies do not standardly regard one another this way. This may be particularly true in moral controversies. But let us put aside controversies over purely moral matters. At this point in our understanding of morality, it's unclear whether moral judgments express straightforwardly factual claims, non-cognitive attitudes, or something in between. Since there are plenty of straightforwardly factual claims that are subject to political controversy, we may avoid some complications by focusing there.

I should emphasize that I'll have to work with example controversies in artificially simplified form. For each example I'll discuss, people accept or deny significantly different versions of the central claim, and for significantly different reasons. The complexity of the evidence and arguments relevant to the issues, and of the social facts about the distribution of opinions on these issues, make a serious, detailed treatment of any of them well beyond what I could attempt here. Instead, I'll work with fairly crude caricatures of the debates, in order to illustrate some general patterns of argument.

One example of a factual claim that's politically controversial, and subject to widespread disagreement in the U.S., is:

Evolution: Humans arose by evolution from earlier life forms.

Now I happen to be a firm believer in Evolution, but I know that many people - some of them very intelligent - disagree. In this case, I not only don't find my confidence shaken by the dissent of Evolution-deniers, but I also don't think my confidence should be shaken. Is this position consistent with IBC? 
It seems to me that it is. Even though close to half of my fellow U.S. citizens disagree with $\mathrm{me}^{13}$, IBC does allow me to give a steadfast response to this case. Looking at the reason why will, I think, begin to reveal the complexities involved in applying IBC to certain sorts of politically charged matters.

One might think that I have an easy answer to the evolution-deniers. After all, I take the question of human origins to be a biological/historical question to be approached through an understanding of how biological forms arise in nature, study of the fossil record, etc. And it's clear that the vast majority of experts on this-paleontologists and evolutionary biologists, that is-believe that humans arose through evolution. This does not seem to be a question like the status of Closure principles for rational belief, where the expert opinion is much more evenly divided. And this near-unanimity of paleontological/evolutionary biological opinion is a fact quite independent of the matter under dispute; everyone acknowledges it. So it can figure in the dispute-independent evaluation of the Evolution-deniers' epistemic credentials that IBC asks me to perform.

But things are not quite this simple. There is a common sort of Evolution-denier who poses a challenge to the Evolution-believer that cannot be answered this way. The theory of evolution conflicts with certain fundamentalist religious views that many Americans subscribe to. Some such fundamentalists deny that science has any purchase at all when it conflicts with certain ancient texts. This sort of Evolution-denier holds that the ancient texts, taken literally, reveal truths, and that science can at best fill in gaps left open by the texts. Some advocates of this position hold, for instance, that the Earth is less than 10,000 years old, basing this claim on a

${ }^{13}$ A 2012 Gallup poll showed 46\% believing that "God created human beings pretty much in their present form at one time within the last 10,000 years or so" (http://www.gallup.com/poll/155003/Hold-Creationist-View-Human-Origins.aspx, accessed $6 / 12 / 12)$. 
literal interpretation of certain ancient religious writings. On this sort of view, adherence to the correct version of the correct religion is a prerequisite to arriving at accurate beliefs about the world. Paleontologists who reject the literal truth of the ancient texts are, on this view, no experts at all. So it looks like I cannot after all take these people's disregard for expert opinion as a dispute-neutral way of negatively assessing their epistemic credentials.

Now my strong instinct is to see such people's strong emotional attachments to their religious views as irrational influences which interfere with their ability to let their beliefs be guided by their evidence. In this respect, I regard their judgments about human origins in much the way I regard Aksel's father's judgments about Aksel's musical talent. But my attitude here brings up a difficult question concerning IBC. In the case of Aksel's father, it's unlikely that he'd dispute my general belief that parents overrate their own children, even if he didn't believe that his own judgment of Aksel's performance was a product of this sort of distortion. So this general fact about parental bias can figure in a dispute-independent evaluation saying that I am more likely to reach the correct conclusion from the evidence that Aksel's father and I share. Does the same apply to my view that religious attachments distort good reasoning? Clearly, this belief of mine would be rejected by the Evolution-deniers in question; in effect, it's part of what's in dispute between us. So it does not seem to be a dispute-neutral claim that I can use in the sort of evaluation mandated by IBC.

What, then, does IBC say about my disagreement with such people? I think it's not at all clear that I can treat their disagreement the way I treat my disagreement with Aksel's father. The issues in dispute between us do not obviously provide for a strong dispute-neutral assessment to the effect that they're less likely to get at the truth. After all, the scientific method, which I take as my fundamental standard for forming beliefs about the world, is treated by them as secondary, 
to be violated whenever its deliverances conflict with certain texts. So no ordinary empirical argument challenging the inerrancy of the texts will count as neutral.

On the other hand, it's also not at all clear that I should treat my disagreement with these Evolution-deniers like I treat my disagreement with those who believe in Closure. The Closure fans and I share the basic assumption that factors such as intelligence and familiarity with the literature are what, if anything, would allow a person to form accurate beliefs about epistemology. So my epistemic respect for Closure fans is founded on my own dispute-neutral positive reasons for granting them that respect. But that's not at all obviously present in the case of the Evolution-deniers: I don't seem to have a strong dispute-independent basis for taking them as peers - to be equally likely to get at the truth.

To see what IBC — as formulated above — says about this sort of case, it's important to recall a key structural aspect of the view. It does not say that I must revise my belief whenever I lack dispute-independent reason to think myself more likely to get it right than my opponents. It says (roughly) that I must revise my belief when I have strong dispute-independent reason to think that my opponents are equally (or more) likely to get it right. So the idea is not that others, simply in virtue of having beliefs, are granted some sort of default status as my epistemic peers, status that they retain absent independent reason to demote them. The epistemic respect I owe to other believers must be earned. In cases where the beliefs of others undermine my initial confidence in some matter, the undermining is ultimately based on my own positive (disputeindependent) reasons for thinking the others likely to get the disputed matter right. If that is 
lacking in the case of certain Evolution-deniers, IBC does not recommend a conciliatory attitude toward their beliefs. ${ }^{14}$

So here we seem to get a clear contrast between standard disputes in academic philosophy, and at least one sort of political controversy. In the case of this sort of political disagreements, it does not seem that much conciliation is required by IBC. (Of course, Mill's argument will still tell us to confront their arguments; but if my confidence emerges from that encounter unshaken, so much the better for my opinion.)

\section{IBC and Public Controversies in Politics 2: Economics}

I would not want to suggest, however, that all politically charged controversies involve challenges to my most basic assumptions about how to form beliefs about the world. Many political disputes, for example, turn in large part on economic questions. In the U.S., disputes often trade on questions about the differential effects that policies have on different economic strata. Progressive income tax rates, on which the wealthy pay a greater percentage of their income than poorer citizens, seem to benefit the poor. But some argue that cutting taxes on the wealthy will actually stimulate the general economy to the extent that the poor will end up benefiting. So there's controversy about:

Tax Cuts: Cutting taxes on wealthy Americans will benefit poor Americans.

\footnotetext{
${ }^{14}$ I should note that not all Conciliationist writers who invoke independence requirements see things this way. It is natural to state the Conciliationist position by saying that revision is required when we lack independent reason for downgrading those who disagree. (And of course lacking independent reason to downgrade and having independent reason for respect will typically coincide.) But it seems to me that the negative formulation leads to skepticism, and misses the point that the mandate to revise in clear cases like Mental Math rests on one's own strong positive reasons for thinking the other person reliable. See (Christensen 2010) for more detail on this.
} 
For another example, minimum-wage laws are designed to protect the lowest-paid workers. But some argue that they increase unemployment to the extent that they end up hurting those they're intended to help. So there's controversy about:

Minimum Wage: Raising the minimum wage will benefit poor Americans.

In these cases, none of the disputants are challenging the claim that the questions are to be settled by empirical means. So how should one's beliefs be affected by this sort of controversy?

We should first notice that the sort of empirical arguments that bear on these economic questions are well beyond the reach of most Americans. So it's not clear that the opinions of ordinary Americans are the most relevant epistemically; most Americans are simply not wellinformed.

It might seem that politicians and government officials responsible for economic policy would be well-informed, and hence that I should give epistemic respect to their opinions. And it is true that many such people have access to economic experts, even if they know relatively little economic theory themselves. Even so, there are reasons to be careful here. It's far from clear that the opinions many such people announce actually express their own views. Politicians say what they need to say to please their voters and financial backers. And appointed government officials avoid saying things that their politician bosses will fire them for saying. So while it may be that many politicians and government officials are relatively well-informed about economic matters, it is less clear that I have very strong reason to take their expressed disagreement with my opinions as a reason for revision. In political disputes, much more than in disputes within academic philosophy, we often have reason to suspect the honesty of the disputants. 
Of course, there are economic experts whom I have more reason to take as being sincere. For example, senior academic research economists occupy protected positions, and can generally say what they like. So I cannot dismiss their pronouncements as easily as I might dismiss those of the politicians and government officials.

In some cases, positions which are controversial politically may not be nearly as controversial among academic economists. Suppose, for instance, that while American politicians are divided on the question, the vast majority of research economists agree that cutting taxes on the wealthy will end up hurting lower-income Americans. If I'm initially inclined toward this position, the wider political controversy may not provide much reason for me to revise my belief. (Of course, if my initial belief is opposite to that of the research economists, I may be under rational pressure to revise.) But the wider political controversy per se may not be all that epistemically significant.

In other cases, though, controversy may penetrate to the academic economists themselves. Consider the claim that raising the minimum wage would benefit lower-income Americans. Let us suppose that in this case, the experts are roughly evenly divided, and that I have dispute-independent reason to accord economists on both sides a high degree of epistemic respect. And let us suppose that I'm inclined to believe the liberal side of the debate, and vote for, and maybe give money to, politicians who would raise the minimum wage. Should I revise my belief in light of the disagreement?

In this case, the disagreement does seem to provide me with a reason to moderate my opinion. On the assumption that I have reason to identify a certain group of people as highly intelligent and knowledgeable, and to think them honest in expressing their opinions, it seems that disagreement among them may well put a limit on the rational confidence I can have on the 
relevant issues. My initial inclination to believe the liberal position that raising the minimum wage would benefit the poor may be no more rationally sustainable, once I'm aware of expert disagreement, than my inclination to reject Closure principles for justification. If that's right, then perhaps I shouldn't be spending much of my money or political energy trying to support politicians who would raise the minimum wage.

But even here, there are more complications. Suppose I'm initially inclined toward the liberal position on minimum wage laws, and suppose I think as follows: "Economists are humans, and so subject to non-rational influences on their beliefs. In general, unconstrained employment benefits the better-off, and economists tend to be well-off. One might predict that, when the empirical evidence is somewhat open to interpretation, self-interest will tend to lead some economists to reach conclusions in line with their self-interest, in effect creating a bias toward conservative conclusions. Since I have dispute-independent reason to expect economists' beliefs to be biased in this way, I may correct for this expected bias, and give less weight to the opinions of conservative economists."

On the other hand, suppose I'm initially inclined toward the conservative position on minimum-wage laws, and think like this: "People's beliefs are often influenced by the group with which they identify-for instance, the liberal group or the conservative group. It's wellknown that university faculty in the U.S. tend to have more liberal views than the population at large. And people will be more likely to hire members of their own group. So universities are subject to systematic bias against conservative views. Since I have dispute-independent reason to expect academic economists' beliefs to be biased in this way, I may correct for this expected bias and give less weight to the opinions of liberal economists." 
Both of these trains of argument are, of course, gross caricatures. But I think that they do represent types of argument that are not uncommon in politically charged disputes. And without going into the details or merits of either one, I think that we can see something important about the structure of this sort of argument. In both cases, the arguer presents reasons for discrediting those with whom she disagrees, and the reasons are —at least at first blush—independent of the matter under dispute. Thus this sort of argument presents another possible way that the rational pressure for belief-revision generated by IBC may be reduced in politically-charged controversies.

Of course, it's one thing to point to the possibility of offering dispute-independent rational grounds for discrediting one's political opponents, and another to say in a given case that one has really done so. Whether one has or has not will of course vary widely across examples, and we shouldn't expect there to be some simple recipe for generating this sort of argument, or for assessing the cogency of particular examples. The present point is that this sort of response is much more natural in thinking about politically important issues than, say, in thinking about Closure in epistemology.

I suspect that discrediting one's opponents' opinions in this way is more natural in politics, at least in part, because it's more often legitimate. Political controversies involve matters of great practical importance. The high practical stakes raise the emotional temperature, and thus invite bias, through self-interest, group-identification, and other emotionally powerful distorters of rational thought. ${ }^{15}$

${ }^{15}$ Of course, beliefs in philosophy are hardly immune from irrational influences. And some of these may even be emotionally powerful—for example, if a philosopher has a long history of supporting a certain position, it could be painful to admit that he was wrong when he encountered strong arguments pointing in that direction. (Thanks to Nathan Ballantyne for 
So we've seen a way in which the political nature of certain disputes can make it more likely that one has grounds for selectively discrediting one's opponents. And when that discrediting is independent of the matter under dispute, it may reduce the IRC-mandated pressure to revise one's beliefs. But one final point about this sort of maneuver deserves noticing. And that is that it will often be unclear to what extent one really has strong independent reasons for discrediting one's opponents.

Consider the liberal who believes that conservative economists are biased by self-interest. She is relying on unquantified common-sense psychology in supposing that self-interest plays a large enough role in conservative economists' thinking to produce a significant bias in favor of policies that benefit the wealthy. Now there's nothing wrong with common-sense psychology: it seems quite legitimate when I use it to discredit the opinion of Aksel's father. But here's another bit of common-sense psychology: people tend to interpret evidence in a way that supports beliefs they already have, especially when those beliefs are important to them. And we can see that discrediting our opponents is an indirect way of supporting our initial beliefs. This suggests that we are likely to be prone to overestimating the degree to which our independent evidence supports downgrading the epistemic credentials of those with whom we disagree.

The problem is exacerbated by the complexity of our epistemic task in applying IBC. As hard as it is to arrive at rational all-things-considered judgments about complex matters in general, here our task is a bit more complex: we must arrive at judgments about what's supported by that subset of our reasons that are independent of the reasoning under dispute. We must focus on the dispute in order to judge how strongly our dispute-independent reasons speak for according epistemic respect to those on the other side.

emphasizing this to me.) That said, I think it will be relatively rare that this sort of distortion can be cited selectively, to discredit one's opponents but not those with whom one agrees. 
The difficulty of doing this is, of course, yet a further facet of our fallibility, against which we should take precautions. In applying IBC, we must beware of letting ourselves off the hook too easily. We probably should often be more generous in our epistemic assessments of our opponents than we might otherwise be inclined to be, especially when we're emotionally invested in our side of the dispute. And this argues for expanding the amount of conciliation we do beyond what might seem to be required by a naive application of IBC to many political controversies.

\section{Conclusion}

IBC, like Mill's argument, makes the disagreement of others an important tool to be used in taking precautions against our epistemic fallibility. IBC stems from seeing that fallibility goes well beyond our failure to notice or respond carefully to considerations which count against our beliefs. It extends to our failure to reason reliably, even when we take all available considerations into account as carefully and conscientiously as we humanly can. Unlike Mill's argument, IBC will often push us toward reduced confidence in disputed matters.

We have seen some ways in which, when we scale up IBC from toy cases to actual cases of widespread group disagreement, the pressure towards conciliation is increased. That's in part because the argument for reducing confidence in the products of our investigative methods need not depend on scoring individuals' track-records, or even identifying very specifically the factors which allow people to arrive at accurate beliefs. And it's in part because the asymmetries of personal information that allow us to dismiss disagreements in some two-person cases disappear in group disagreements. We can see these points in the case of philosophical controversy.

When we move to political controversy, though, things get more complicated in some ways that reduce the pressure towards conciliation. With respect to many issues of political 
controversy, dispute-independent epistemic evaluation of the parties to the disagreement is particularly difficult. In some cases (such as those involving religious fundamentalism) there may be too little material that's independent of the dispute to provide strong reason for granting epistemic respect to those with whom one disagrees. In such cases, there may be very little reason, even given IBC, for reducing confidence in one's beliefs.

In other cases of political controversy, one may have dispute-independent reason to think less well of one's opponents. One may have reason to believe that they're ill-informed; that their pronouncements don't reflect their true opinions; or that their thinking is distorted by selfinterest, group-identification, or other biasing factors. To the extent that such reasons are strong, the IBC-based mandate for reducing confidence is weakened.

But these cases, which I suspect are very common in political disputes, present special difficulties. For a thorough acknowledgment of our fallibility surely includes acknowledging fallibility in assessing the degree to which dispute-independent factors favor our own reliability over that of our opponents. And once this is taken to heart, the confidence-lowering effects of conscientiously applying IBC in cases of political disagreement become more severe than one might have hoped they would be.

To the extent that this means that our political decisions will inevitably depend on a less secure picture of what the world is like, this is bound to be frustrating, as it is in philosophy. But surely we should remain mindful of the downside of taking bold actions based on mistaken confidence in politically important matters. Given the unfortunate fact of our fallibility, we should take Mill's advice, and avail ourselves of such precautions against it as we can find. Even if, in the end, confronting disagreement reduces, rather than bolsters, our rational confidence about important matters, disagreement is a valuable epistemic resource. We should be grateful 
that diversity of opinion can serve us as a warning sign, indicating issues on which our thinking is especially likely to have gone astray.

\section{David Christensen \\ Brown University}




\section{References}

Brennan, J. (2010), “Scepticism about Philosophy.” Ratio 23, 1-16.

Chalmers, D. J. (2011), “Verbal Disputes,” Philosophical Review 120: 515-566.

Christensen, D. (2007), "Epistemology of Disagreement: the Good News," Philosophical Review 116: $187-217$.

---. (2011), "Disagreement, Question-Begging and Epistemic Self-Criticism," Philosophers' Imprint: 1-22.

---. (2013), "Epistemic Modesty Defended,” in Christensen and Lackey.

Christensen, D. and J. Lackey, eds. (2013), Disagreement: New Essays (Oxford: Oxford University Press).

Elga, A. (2007), "Reflection and Disagreement,” Noûs 41: 478-502.

---. (2010), “How to Disagree about how to Disagree," in Feldman and Warfield.

Feldman, R. and T. Warfield, eds. (2010), Disagreement (Oxford: Oxford University Press).

Frances, B. (2010), “The Reflective Epistemic Renegade," Philosophy and Phenomenological Research LXXXI, 2: 419-463.

Fumerton, R. (2010), "You Can’t Trust a Philosopher," in Feldman and Warfield.

Goldberg, S. (2013), “Disagreement, Defeaters, and Assertion,” Christensen and Lackey.

---. (2009), "Reliabilism in Philosophy.” Philosophical Studies 124: 1, 105-17.

Kornblith, H. (2010), "Belief in the Face of Controversy," in Feldman and Warfield.

Lackey, J. (2010), “A Justificationist View of Disagreement's Epistemic Significance”, in A. Haddock, A. Millar, and D. Pritchard (eds.), Social Epistemology (Oxford: Oxford University Press). 
Mill, J. S. (1859), On Liberty (Indianapolis: Bobbs-Merrill, 1956).

Sosa, E (2010), "The Epistemology of Disagreement," in in A. Haddock, A. Millar, and D. Pritchard (eds.), Social Epistemology (Oxford: Oxford University Press).

Spener, M. (2011), "Disagreement about Cognitive Phenomenology," in Cognitive Phenomenology, T. Bayne \& M. Montague (eds.), Oxford University Press.

Weatherson, B. (2013), "Disagreements, Philosophical and Otherwise," in Christensen and Lackey. 